\title{
MICROSCALE OBSERVATION AND MODELING OF SOIL-STRUCTURE INTERFACE BEHAVIOR USING PARTICLE IMAGE VELOCIMETRY
}

\author{
JASOn T. DeJong ${ }^{\mathrm{i})}$, DAvid J. Whiteii) and Mark F. RANDOLPHiii)
}

\begin{abstract}
The shearing behavior of a soil-structure interface governs the response of many geotechnical systems, in particular piled foundations. The shaft resistance of piled foundations is known to degrade with cyclic loading, although the governing mechanism is not well understood. This paper presents the results of a laboratory soil-structure investigation in which internal specimen deformations were obtained using particle image velocimetry (PIV) and the normal confining stress was permitted to vary according to a constant normal stiffness (CNS) condition. The PIV measurements showed the shear deformation and volume change to be concentrated within a shear band with a thickness of 5-7 particle diameters adjacent to the interface. During a single cycle the volume change within the shear band began with an initial contraction, followed by dilation to the failure envelop. For the cycling amplitude investigated this response led to a net specimen contraction. The benefit of quantifying the thickness and contraction of the shear band using PIV is that the progressive decrease in void ratio of the shear band can be linked to the limiting value imposed by the minimum void ratio. This provides a framework in which the contraction of the specimen depends on the potential contraction expressed as the difference between the current and minimum void ratio. A model for this contraction is presented, and linked to the decay in normal stress and the limiting loss of interface friction. This framework clarifies the mechanism of friction fatigue during installation and loading of displacement piles in sand.
\end{abstract}

Key words: CNS, constant normal stiffness, cyclic degradation, cyclic shear, GeoPIV, interface shear, load transfer, particle image velocimetry, PIV, planar deformations (IGC: D7)

\section{INTRODUCTION}

Soil-structure interface behavior is critical for determining the frictional load transfer for constructions such as axially loaded piles, tunneling, and geosynthetics, where the normal stresses are difficult to deduce directly, and will evolve during cyclic loading. Early research into soil-structure interface strength focused on conditions of monotonic shear and led to design criteria linked to the soil type and interface material (e.g. Potyondy, 1961; Paikowsky et al., 1995; Lee, 1998). As field and laboratory data of cyclic soil-structure interface loading emerged, in particular from offshore foundation systems, it was acknowledged that under cyclic loading conditions the interface strength decreased, primarily due to the reduction in normal stress (Poulos, 1989).

The limited understanding of cyclic strength degradation and its controlling parameters led to the expansion of interface research into cyclic shearing modes, and encompassed the soil types most vulnerable to degradation (calcareous and cemented soils), and the boundary stress conditions appropriate to piled foundations (constant normal stiffness: Boulon and Foray, 1986; Johnston et al., 1987). A wide variety of laboratory tests have been used to examine soil-structure interface behavior (e.g. direct shear interface tests: Airey et al., 1992; Shahrour and Rezaie, 1999; ring shear interface tests: Tabucannon, 1997; rod shear and model pile tests: Jewell and Randolph, 1989) generating external measurements that reflect the global specimen behavior. These observations at the specimen boundary, remote from the interface, have successfully characterized many behavioral trends, but further understanding requires more detailed knowledge of the displacement and strain fields adjacent to the interface.

Recently particle image velocimetry, an image-based deformation measurement technique, was adapted for geotechnical modeling (referred to as GeoPIV: White, 2002; White et al., 2003). This system was used to analyze a series of monotonic and cyclic constant normal stiffness interface shear tests conducted on sand in a transparentsided interface shear apparatus (DeJong et al., 2003). The distribution of displacements and strains adjacent to the interface was quantified. It was found that the deforma-

i) Assistant Professor, Civil and Environmental Engineering, University of California, Davis, CA 95616, USA (jdejong@ucdavis.edu).

ii) University Lecturer, Cambridge University Engineering Department, Cambridge CB2 1PZ, United Kingdom (djw29@eng.cam.ac.uk).

iii) Professor of Civil Engineering and Director of the Center for Offshore Foundation Systems, University of Western Australia, Stirling Highway, Nedlands, WA 6907, Australia (randolph@civil.uwa.edu.au).

The manuscript for this paper was received for review on September 7, 2004; approved on November 10, 2005.

Written discussions on this paper should be submitted before September 1, 2006 to the Japanese Geotechnical Society, 4-38-2, Sengoku, Bunkyo-ku, Tokyo 112-0011, Japan. Upon request the closing date may be extended one month. 
tion was localized within a distinct shear band with a thickness of 5-10 particle diameters, the remainder of the specimen remaining essentially rigid. The net, or total, deformation that occurred over one cycle (e.g. from $+1.0 \mathrm{~mm}$ to $-1.0 \mathrm{~mm}$ ) and how this was influenced by the cementation condition (uncemented versus cemented), shearing mode (monotonic versus cyclic), shearing condition (stress versus displacement controlled), shearing magnitude, and soil type (silica versus calcareous sand) were investigated. Also quantified were the thickness, volumetric and shear strains, and secant shear modulus of the shear band, as well as the percent slip that appeared to occur directly at the soilstructure interface. This study allowed comparison of the local behavior within the shear band and the global specimen response conventionally obtained.

The previous work concentrated on the net behavior over an entire cycle. This detail is insufficient for the development of a full model of interface behavior that would allow predictions of arbitrary cycles of loading. For example, the interface initially contracts and then dilates within each cycle. Therefore, the trends of net deformation per cycle with cyclic displacement amplitude will be non-linear, and the incremental behavior within an individual cycle should be modeled.

In accordance with this approach, the objective of this paper is to quantify both the evolution of the net behavior over multiple cycles and the behavior within individual cycles during interface shear. Further analysis of the tests initially reported by DeJong et al. (2003) is presented. The global and local responses are compared, and the development of displacements and strains throughout the specimen within a single cycle is presented. The local observations of shear band deformation permitted by GeoPIV analysis through the apparatus window allow the void ratio of the shear band to be measured, knowing the initial and current thickness and the initial specimen conditions. This information overcomes the limitation of global measurements, which obtain average responses over the interface region and the remaining 'passive' portion of the specimen. A simple model is proposed to capture net specimen contraction, and hence reduction in interface strength, with cycle number. This contraction rate is linked to the maximum specimen density (minimum void ratio) hypothesized as a minimum voids ratio line parallel to the critical state line. This approach allows a lower limit on the degradation of interface strength to be evaluated for a given confining stiffness and normal stress.

\section{FACTORS AFFECTING CYCLIC INTERFACE BEHAVIOR}

Of central importance to cyclic interface behavior is the decrease in mobilized shear strength with cycling. The rate of cyclic degradation, which can be defined as the decrease in shear stress at failure (or limiting displacement) with the number of cycles, has been shown to be dependent on the confinement condition of the soil-struc- ture interface. In sand, the shear stress at failure, $\tau_{\mathrm{f}}$, can be expressed as the product of the normal effective stress at failure, $\sigma_{\mathrm{nf}}^{\prime}$, and the coefficient of friction, $\mu$ (or $\tan \delta$ ). Cumulative cyclic displacement can lead to some reduction in the interface friction angle from peak to constant volume (or critical state) conditions, but a larger contribution to the degradation arises from the loss of normal stress around cylindrical objects such as piles. The reduction in $\sigma_{\mathrm{n}}$ arises because in axial symmetry radial movement at the interface leads to a change in normal stress. This confinement condition can be simulated by a constant normal stiffness (CNS), which incorporates an initial normal stress coupled with a spring (Boulon and Foray, 1986). The spring stiffness replicates the far-field stiffness around a cylindrical pile, and is generally assumed to be constant, implying elastic soil response. The normal stress at any point during CNS shearing is determined by:

$$
\sigma_{\mathrm{ni}}=\sigma_{\mathrm{n} 0}-\Delta z k=\sigma_{\mathrm{n} 0}-\Delta z(4 G / d)
$$

where $\sigma_{\mathrm{ni}}$ is the current normal stress on the interface, $\sigma_{\mathrm{n} 0}$ is the initial normal stress, $\Delta z$ is the deformation of the specimen normal to the interface (reflecting contraction $(+\mathrm{ve})$ or dilation $(-\mathrm{ve})), k$ is the spring stiffness (reflecting the elastic response of the far-field), $G$ is the operative shear stiffness of the far-field soil, and $d$ is the pile diameter (Johnston et al., 1987). The limiting conditions of CNS where $k$ is equal to 0 or $\infty$ reflect constant normal load (CNL) and constant normal height $(\mathrm{CNH})$ conditions, respectively.

The CNS condition gives a reduction in the normal stress as the interface shear band contracts, in turn resulting in a decrease in the limiting interface shear stress (or shaft resistance). Consequently, factors that influence volume change of the interface shear band in turn affect the magnitude of normal and hence limiting shear stress. The influence of factors including $\sigma_{\mathrm{n} 0}, k$, soil type, soil density, interface surface roughness, and magnitude of loading have been examined through conventional measurements of global specimen response (Airey et al., 1992; Tabucannon et al., 1995; Tabucannon, 1997; Shahrour and Rezaie, 1999; Kelly, 2001).

\section{EXPERIMENTAL INVESTIGATION}

The results presented here focus on four tests that allow the influence of cementation, shearing mode, and soil type to be examined based on global and local measurements between and within cycles (Table 1). Test $\mathrm{t} 074 \mathrm{c}$, in which an uncemented silica sand is sheared under displacement controlled conditions $(+/-1 \mathrm{~mm})$, is the reference test. Tests t076c, t072c, and t075c highlight the influence of cementation, shearing mode (displacement or load-controlled), and soil type, respectively. Descriptions of the test program including the soil type, method of preparation, apparatus description, image capture method, and GeoPIV analysis are presented below and additional detail is given by DeJong et al. (2003). 


\section{Testing Program and Setup}

A custom interface direct shear device for soil specimens of size $60 \times 100 \mathrm{~mm}$ in plan and approximately $20 \mathrm{~mm}$ in height was used to enable interface shearing (Fig. 1). A $12 \mathrm{~mm}$ thick Perspex window that extended along the length of one side of the shear box enabled continuous image capture for PIV analysis. It is noted that since the soil-Perspex friction angle is significantly lower than the soil-soil friction angle and that observations showed particles to slide behind the Perspex window, it was assumed that behavior observed at the window is representative of the full cross-section of the specimen. The top platen was fixed to the loading piston to prevent particle movements in the upper portion of the specimen due to platen rotation. Restraint rollers maintained a shear box-interface gap of $1 / 2 D_{50}$, preventing soil particles from escaping between the shear box and interface plate hence eliminating artificial volumetric changes. These measures, intended to better replicate in situ conditions (e.g. adjacent to a pile shaft), also impose additional constraints on the specimen, yielding slightly higher friction coefficients than would otherwise be obtained (Kelly, 2001; Dietz, 2001).

Imdex 16-30, a uniform subrounded silica sand $\left(D_{50}=\right.$ $\left.0.73 \mathrm{~mm}, e_{\min }=0.500, e_{\max }=0.679\right)$, and LeGendre $16-30$, an artificially graded angular calcareous sand $\left(D_{50}=0.83\right.$ $\left.\mathrm{mm}, e_{\min }=0.639, e_{\max }=0.957\right)$, were prepared at a medium dense state $\left(D_{\mathrm{r}} \approx 60-65 \%\right.$, Imdex $e_{0} \approx 0.567$, LeGendre $e_{0} \approx 0.758$ ) by tamping. The cemented test specimen $(\mathrm{t} 075 \mathrm{c})$ was prepared by mixing a $1 \%$ gypsum $-4 \%$ water (relative to sand weight) solution with dry sand, moist tamping the specimen to the required density, and curing the specimen for 12 hours under the initial normal load $\left(\sigma_{\mathrm{n} 0}\right)$.

Standard direct shear testing procedures were followed. The interface shear box and the vertical constraint rollers were assembled and the specimen prepared. Shearing was induced in the specimen by displacement of the fully rough interface surface. A closed loop data acquisition and control program was used to apply the CNS condition $\left(\sigma_{\mathrm{no}}=100 \mathrm{kPa}, k=250 \mathrm{kPa} / \mathrm{mm}\right)$, maintain a displacement rate of $0.5 \mathrm{~mm} / \mathrm{min}$, detect the cycling limits $(+/-1.0 \mathrm{~mm}$ or $+/-125 \mathrm{kPa})$, and acquire global displacement and stress measurements every $0.01 \mathrm{~mm}$ of displacement. For all tests 45 cycles were performed.

\section{Particle Image Velocimetry}

GeoPIV (White, 2002; White et al., 2003) was used to quantify the displacement and strain fields, tracking the inherent texture (i.e. spatial variation of brightness) of soil grains through a series of images without the need of discrete markers. This is a significant advantage over other methods where markers can either become obstructed during testing or influence the behavior of the specimen, and provides higher precision and accuracy than other non-contact methods previously used in geotechnical testing (White et al., 2003).

A Nikon Coolpix 990 digital still camera was used, with
Table 1. Summary of cyclic CNS interface shear testing program

\begin{tabular}{cccc}
\hline Test \# & Sand type & Cyclic limits & Cementation \\
\hline t074c & IMDEX 16-30 & $\pm 1.0 \mathrm{~mm}$ & Uncemented \\
t076c & IMDEX 16-30 & $\pm 1.0 \mathrm{~mm}$ & Cemented \\
t072c & IMDEX 16-30 & $\pm 125 \mathrm{kPa}$ & Uncemented \\
t075c & LeGendre 16-30 & $\pm 1.0 \mathrm{~mm}$ & Uncemented
\end{tabular}

Confinement Condition: $\sigma_{\text {по }}=100 \mathrm{kPa}, k=250 \mathrm{kPa} / \mathrm{mm}$

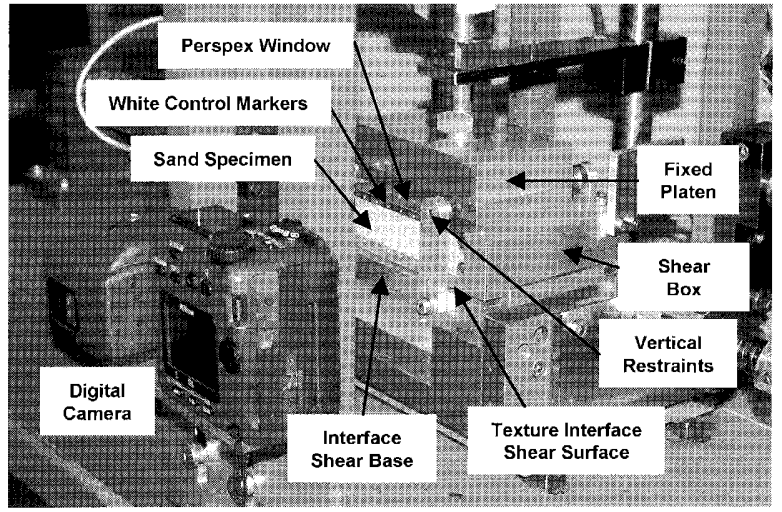

Fig. 1. Setup of modified interface direct shear test with image capture for PIV analysis (DeJong et al., 2003)

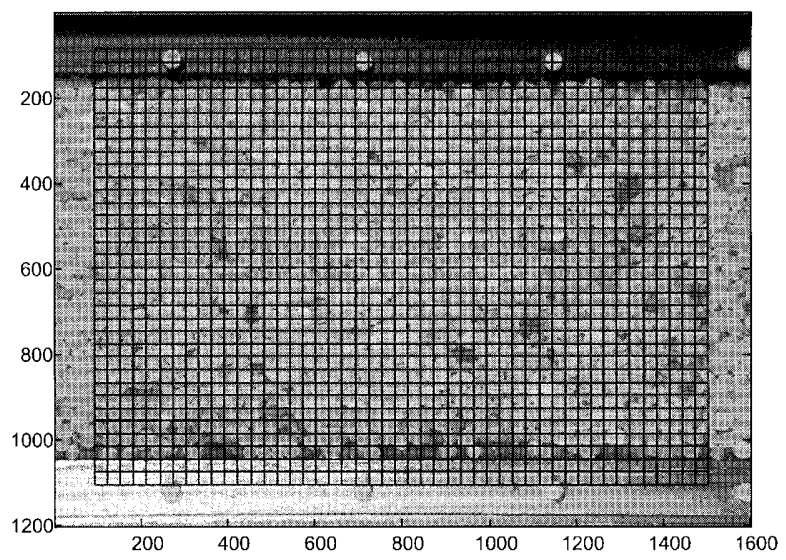

Fig. 2. Plot of $1600 \times 1200$ digital image with white control markers and a $159830 \times 30$ pixel patch PIV mesh

an image resolution of $1600 \times 1200$ pixels, and images were captured through a Perspex side window (Fig. 2) at $0.1 \mathrm{~mm}$ nominal horizontal interface displacement increments and at shearing direction reversals. The field of view $(35.0 \times 26.25 \mathrm{~mm})$ covered the central $1 / 3$ of the specimen and images were obtained throughout cycles $1-5,21-25$, and $41-45$. Analysis of the central $1 / 3$ of the specimen ensured minimal effects from the boundary conditions and behavior most similar to field conditions adjacent to a pile shaft. PIV analysis verified that behavior was indeed uniform across the entire image. For the present analysis, 1,598 patches per image were analyzed (Fig. 2), representing a finer mesh than used previously (DeJong et al., 2003). Based on calibration exercises reported by White et al. (2003), the patch size of $30 \times 30$ 
pixels leads to precision of $\sim 0.02$ pixels, which corresponds to $\sim 0.5 \mu \mathrm{m}$.

To perform the image-space to object-space transformation, white control points were machined into the back of the Perspex window (Figs. 1 and 2). The variation in image scale due to optical distortion was calculated by comparing the separation of adjacent control points in image-space and object-space. The image scale typically varied by $+/-0.3$ pixels $/ \mathrm{mm}$ (average value of 45.4 pixels $/ \mathrm{mm}$ ), which corresponds to a locational accuracy of $+/-0.6 \%$. Image scale variations also arise since the observed soil grains do not comprise a planar surface. Grains contacting the Perspex are closer to the camera than recessed grains visible through voids. The effective projective center of the camera was calculated to be $38 \mathrm{~mm}$ from the inner face of the Perspex window. A second layer of grains positioned $1 / 2 D_{50}$ behind the window (i.e. $\approx 0.36 \mathrm{~mm}$ ) leads to a variation in image scale of approximately $1.1 \%$; this is significantly greater than that created by other sources of image distortion. Therefore, the use of close range photogrammetry to deduce the variation in image scale due to optical distortion was unwarranted. In the analysis herein, the image-space to object-space conversion was made by using a constant image scale of 45.4 pixels $/ \mathrm{mm}$.

Since the image scale remained constant throughout each image sequence, no systematic difference exists between the coordinates of a soil element in subsequent images. Instead, the error in the measured displacement of a soil element derives from the precision of the measurement system, not the accuracy. Therefore, the error in each soil element displacement step is very small and equal to the GeoPIV precision described previously. This error corresponds to a soil displacement of less than $0.5 \mu \mathrm{m}$. The error in the absolute location of each soil element (shown as the vertical axis of Fig. 7) is comparatively large $(+/-0.6 \%)$, and corresponds to $+/-125$ $\mu \mathrm{m}$ over the $20 \mathrm{~mm}$ specimen height. However, the displacements of patches between subsequent images and the average displacements within a patch layer (shown as the horizontal axis of Fig. 7) are governed by the precision rather than the accuracy. Therefore, these measurements have considerably less error, though not as low as the system precision $(0.5 \mu \mathrm{m})$ due to random walk errors associated with cumulative displacement measurements.

With this configuration, GeoPIV analysis of an image sequence produces a precise two-dimensional displacement field across the entire image area, from the interface to the top platen spanning the central third of the specimen. After confirmation of uniform behavior across the lateral extent of the images, the displacements of all patches in each row were averaged to enable presentation of representative displacement behavior as a function of distance from the interface. This representative average displacement data were used as the basis for the following analysis and to generate the plots shown in Fig. 7.

\section{EXPERIMENTAL RESULTS}

\section{Global Specimen Response}

Conventional measurements of normal and shear stress at the interface as well as horizontal interface movement and vertical platen displacement were obtained throughout the 45 cycles in all tests. Cycles 1, 21, and 41 are plotted in Fig. 3, with each column containing data from a different test. The upper two graphs show the conventional shear stress $(\tau)$ and vertical displacement $\left(\delta_{v}\right)$ versus horizontal displacement $\left(\delta_{\mathrm{h}}\right)$ plots, respectively, while the bottom graph presents the normal $\left(\sigma_{n}\right)$ versus shear $(\tau)$ stress response, compared to a failure envelope corresponding to an interface friction angle of $53.7^{\circ}$. As mentioned previously, this value is higher than would be expected in a conventional shear box and is attributed to the increased resistance to shearing added by the use of a fixed top cap and by limiting the shear box-interface gap with restraint rollers.

The global behavior of test t074c (silica sand, uncemented, $\pm 1 \mathrm{~mm}$, Fig. 3(a)) reflect trends typical of CNS cyclic tests (e.g. Airey et al., 1992; Shahrour and Rezaie, 1999). After behavior similar to a monotonic test during initial shearing to $+1.0 \mathrm{~mm}$, cycling results in a steady decrease of the maximum shear stress attained in each cycle due to the accumulation of net contraction and the consequent reduction in normal stress. Each cycle begins with a brief contractile phase before dilation begins and the net effect, over the $+/-1 \mathrm{~mm}$ cycles, is cumulative contraction. Throughout the paper contractive behavior is defined as positive $\delta_{\mathrm{v}}$ (dilation as negative $\delta_{\mathrm{v}}$ ) and the CNS condition is thus implemented as $\sigma_{\mathrm{ni}}=$ $\sigma_{\mathrm{n} 0}-\left(-\delta_{\mathrm{v}}\right) k$, which increases the normal stress with dilation at a rate proportional to $k$. The maximum shear stress $(\tau)$ decreases proportionally to the normal stress $\left(\sigma_{\mathrm{n}}\right)$, assuming the specimen reaches the failure envelope in each cycle and the failure envelope is linear over the relevant stress range. A slight non-linearity of the failure envelope is evident in Fig. 3(a), with a higher coefficient of friction being mobilized at lower normal stresses. This is due to two effects that lead to an increase in friction angle: reduction of normal stress and increase of density (Bolton, 1986).

The degradation of the maximum shear stress, the cumulative contraction, the incremental contraction per cycle, and the vertical cyclic amplitude as measured by sensors external to the specimen is presented in Fig. 4. These plots capture the trends with cycle number indicated by cycles 1, 21, and 41 in Fig. 3. Following cycle 1 , the shear stress decreases in a non-linear manner (Fig. 4(a)). The majority of the degradation occurs in the early cycles and by the end of the displacement-controlled tests the gradients lie between 0.45 and $0.80 \mathrm{kPa} /$ cycle (corresponding to $\sim 0.002$ to $0.003 \mathrm{~mm} / \mathrm{cycle}$ of net contraction). Eventually the incremental contraction must cease, when the material at the interface reaches a minimum void ratio consistent with the (reducing) normal stress. Cementation (t076c) reduces the rate of degradation, while the presence of a more breakable soil 
(a) Test t074c
$+/-1 \mathrm{~mm}$, uncemented, silica
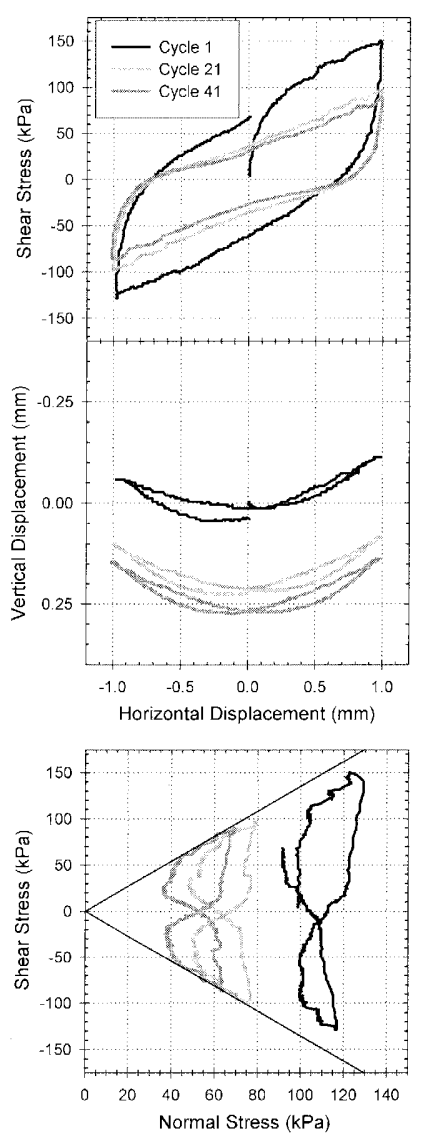

(b)

Test t076c
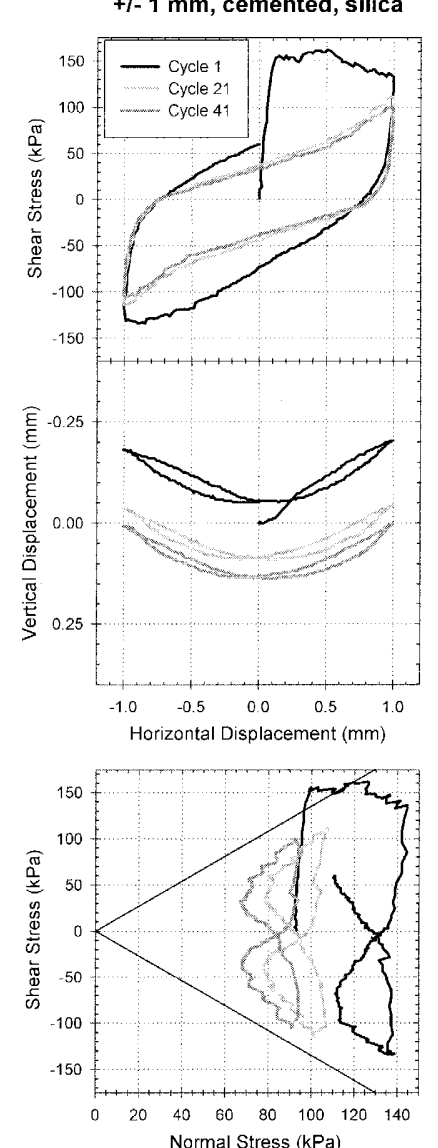

(c)

$+/-125 \mathrm{kPa}$, uncemented, silica

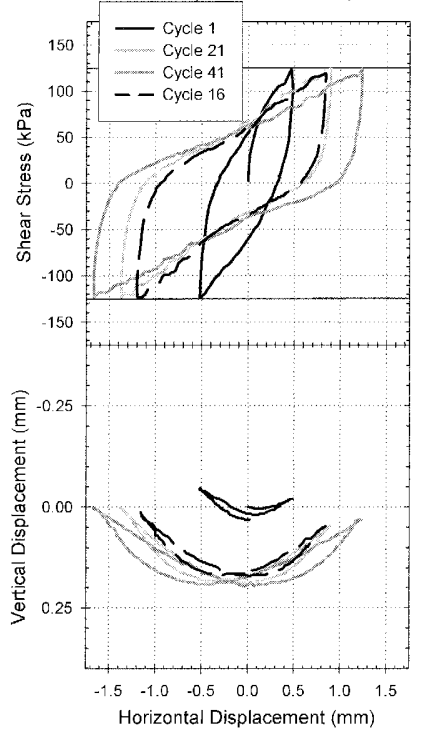

Horizontal Displacement $(\mathrm{mm})$

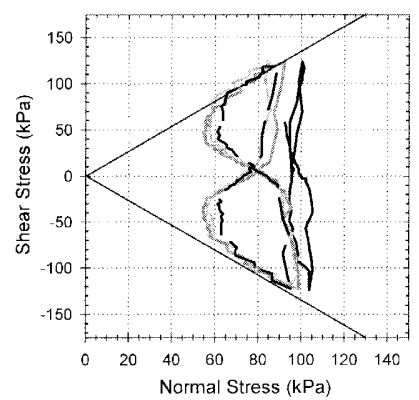

(d) Test to75c

+/- $1 \mathrm{~mm}$, uncemented, calcareous
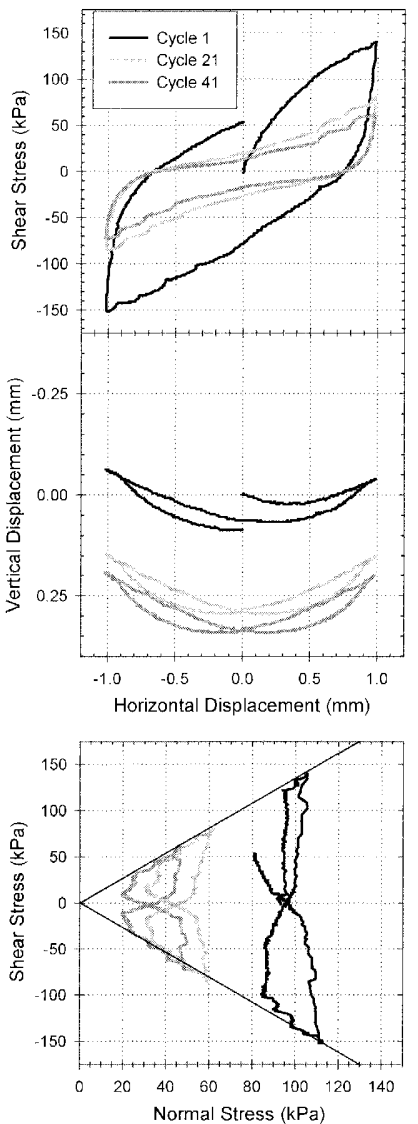

Fig. 3. Summary of global behavior of cyclic interface shear tests (adapted from DeJong et al., 2003)

(calcareous, t075c) increases the rate of degradation.

\section{Evolution of Net Local Behavior with Cycle Number}

The GeoPIV measurements provide the opportunity to observe the local deformations within the specimen and identify where localized behavior was occurring. These local measurements enabled quantitative analysis throughout the specimen height and within the shear band adjacent to the interface using the following definitions:

- Shear band thickness $\left(h_{1}\right)$ : defined as the clearlydelineated zone of significant horizontal displacement gradient (Fig. 5),

- Maximum local shear strain amplitude $\left(\gamma_{\text {amp }}\right): \gamma_{\text {amp }}=$ $\Delta x / h_{\mathrm{t}}$, where $\Delta x$ is the relative horizontal displacement of the top and bottom of the shear band during a cycle and $h_{\mathrm{t}}$ is the thickness of the shear band.

- Maximum volumetric strain amplitude $\left(\varepsilon_{\mathrm{v} \text { amp }}\right): \varepsilon_{\mathrm{v} \text { amp }}$ $=\Delta y / h_{\mathrm{t}}$, where $\Delta y$ is the change in vertical position of the top of the shear band over a given displacement increment and $h_{\mathrm{t}}$ is the initial shear band thickness.

- Secant shear modulus $(G): G=\Delta \tau / \gamma_{\text {amp }}$ over a halfcycle within the shear band, where $\Delta \tau=2 \tau_{\max }$ is determined from Fig. 3 and $\gamma_{\text {amp }}$ is described above.

- Percent slip amplitude at the interface $\left(S_{\mathrm{amp}}\right): S_{\text {amp }}=$ $\delta h_{\text {slip }} / \delta h \times 100$ where $\delta h_{\text {slip }}$ is the amount of slip at the interface (Fig. 5) and $\delta h$ is the total interface displacement. This is the percent difference between interface displacement and maximum soil displacement adjacent to the interface (which is extrapolated to the interface surface from the lowest PIV patch row).

The error within the strain measurements, $\gamma_{\text {amp }}$ and $\varepsilon_{\mathrm{v} \text { amp }}$, arises from random errors of $\sim 0.5 \mu \mathrm{m}$ (the system precision) affecting $\Delta x, \Delta y$ and $h_{\mathrm{t}}$. Since both $h_{\mathrm{t}}$ and $\Delta x$ (over a whole cycle) are $>1 \mathrm{~mm}$, the error in $\gamma_{\mathrm{amp}}=\Delta x / h_{\mathrm{t}}$ is $<0.1 \%$ of the calculated value. $\Delta y$ is $>0.1 \mathrm{~mm}$ over a whole cycle, so the error in $\varepsilon_{\mathrm{v} \text { amp }}=\Delta y / h_{\mathrm{t}}$ is $<1 \%$ of the calculated value. The evolution of each of these parameters as a function of cycle number is shown in Fig. 6. The trends are consistent with the global data (Fig. 4) and indicate substantial changes occurring within the earlier cycles and minor evolution in later cycles. For the uncemented silica sand under displacement controlled shearing ( $\mathrm{t} 074 \mathrm{c})$, the shear band thickness $\left(h_{\mathrm{t}}\right)$ increases during cycling, resulting in more distributed, and therefore slightly lower shear strains $\left(\gamma_{\text {amp }}\right.$ ) (Fig. 6). The rapid decrease in shear stress in early cycles (Fig. 4(a)) results in a decrease in the shear modulus $(G)$, which then stabilizes. The volumetric strain $\left(\varepsilon_{\mathrm{vamp}}\right)$ follows a similar trend to the global total vertical 

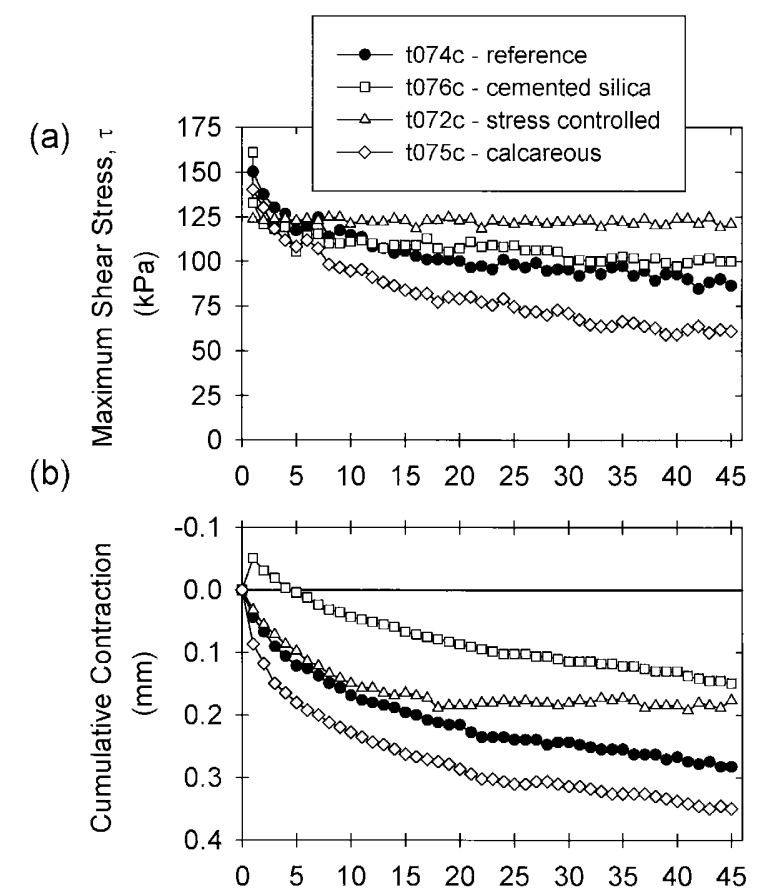

(c)

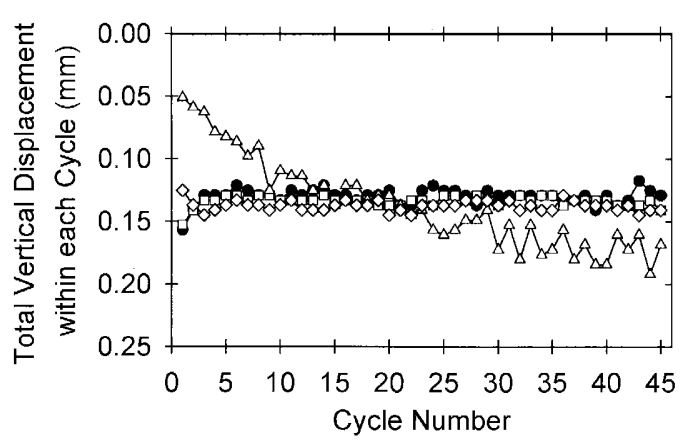

Fig. 4. Global behavior trends during cycling

displacement within each cycle (Fig. 4(c)), with the displacement-controlled tests reaching approximately constant values and the stress-controlled test showing an increasing trend due to the increasing dilation and contraction within each cycle.

\section{Influence of Cementation}

Variations in behavior due to cementation, cycling mode, and soil type are evident in Figs. 3(b), (c) and (d), respectively. The presence of light cementation (t076c, Fig. 3(b)) results in a stiffer initial response, which ends at the onset of particle-particle and particle-interface contact breakage. A peak strength of $150 \mathrm{kPa}$ is mobilized at a movement of $0.15 \mathrm{~mm}$, and remains approximately constant despite continued dilation and a corresponding increase in normal stress. Over the first $1 \mathrm{~mm}$ of displacement, the response is related to cement bond strength and not frictional strength. Following reversal, contraction occurs and the response becomes primarily frictional, with net cyclic contraction mirroring the uncemented test. However, a surprisingly low friction coefficient is evident $(\mu \approx 1.0$ ), suggesting that the friction angle of the broken cemented soil is lower than for the

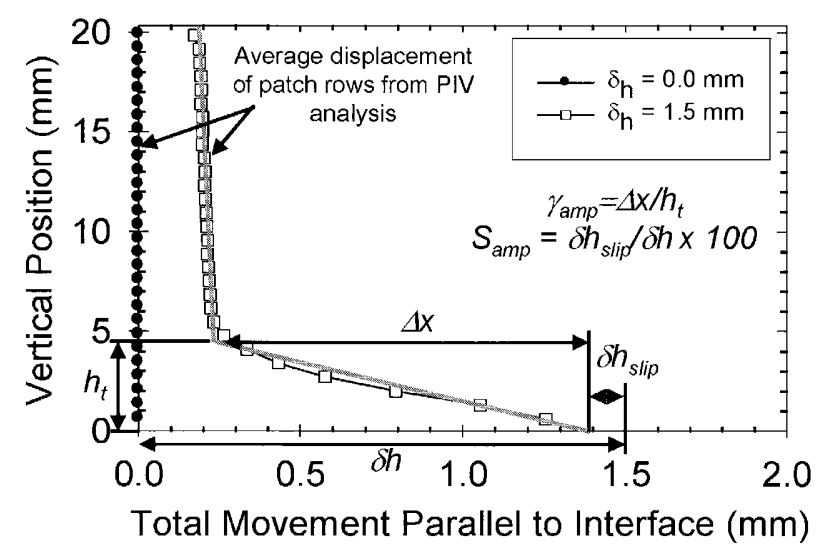

Fig. 5. Schematic of local measurements calculated from average displacement contours of PIV analysis

uncemented soil. From the local measurements (Fig. 6(a)) it is seen that cementation (t076c) results in a narrower shear band $\left(h_{t}\right)$, and hence an increase in $\gamma_{\text {amp }}$ and a decrease in $G$ within the shear band. This greater localization also results in an increased $S_{\text {amp }}$ and slightly higher $\varepsilon_{\mathrm{v} \text { amp }}$ in later cycles.

\section{Influence of Shearing Mode}

Stress-controlled shearing (t072c, Fig. 3(c)) must recoup any contraction that occurs at the start of a given cycle in the subsequent dilation phase in order to mobilize the normal stress necessary to generate a shear stress of $+/-125 \mathrm{kPa}$ in order to complete the cycle. This results in very different volumetric behavior $\left(\delta_{\mathrm{v}}\right.$ versus $\delta_{\mathrm{h}}$ plot $)$ and stress paths ( $\sigma_{\mathrm{n}}$ versus $\tau$ plot) with cycling. Under stress-control, the displacement amplitude increases with increasing cycles due to two effects: firstly, contraction during the first phase of each cycle increases, requiring greater shearing at a given dilation angle to recover the lost volume; secondly, the dilation angle also appears to decrease slightly, requiring greater shearing to recoup a given contraction. Thus the contractile phases of cycles 1 , 21 , and 41 involve vertical settlement of $0.05,0.14$, and $0.18 \mathrm{~mm}$ respectively, and these contractions are recovered over horizontal displacements of $0.4,1.3$, and $1.8 \mathrm{~mm}$, corresponding to mean dilation angles of 7.0, 6.1 , and $5.7^{\circ}$. The local measurements show that stress controlled shearing (t072c) results in increased $\varepsilon_{\mathrm{v} \text { amp }}$ and $\gamma_{\text {amp }}$ with cycling (Figs. 6(b) and (c)), which agrees with the global measurements of greater volume change (Fig. 3). Lower initial values of $\gamma_{\text {amp }}$ in early cycles result in high $G$ values while increased interface displacement results in increased $S_{\text {amp }}$.

\section{Influence of Soil Type}

LeGendre calcareous sand (t075c, Fig. 3(d)), a more angular and crushable soil, exhibits greater volumetric contraction and shear stress degradation. Despite the higher angularity, the stress ratio at failure is comparable to the rounded silica sand. Rapid contraction in the early cycles results in accelerated progression down the failure envelop ( $\sigma_{\mathrm{n}}$ versus $\tau$ plot) towards a maximum shear 

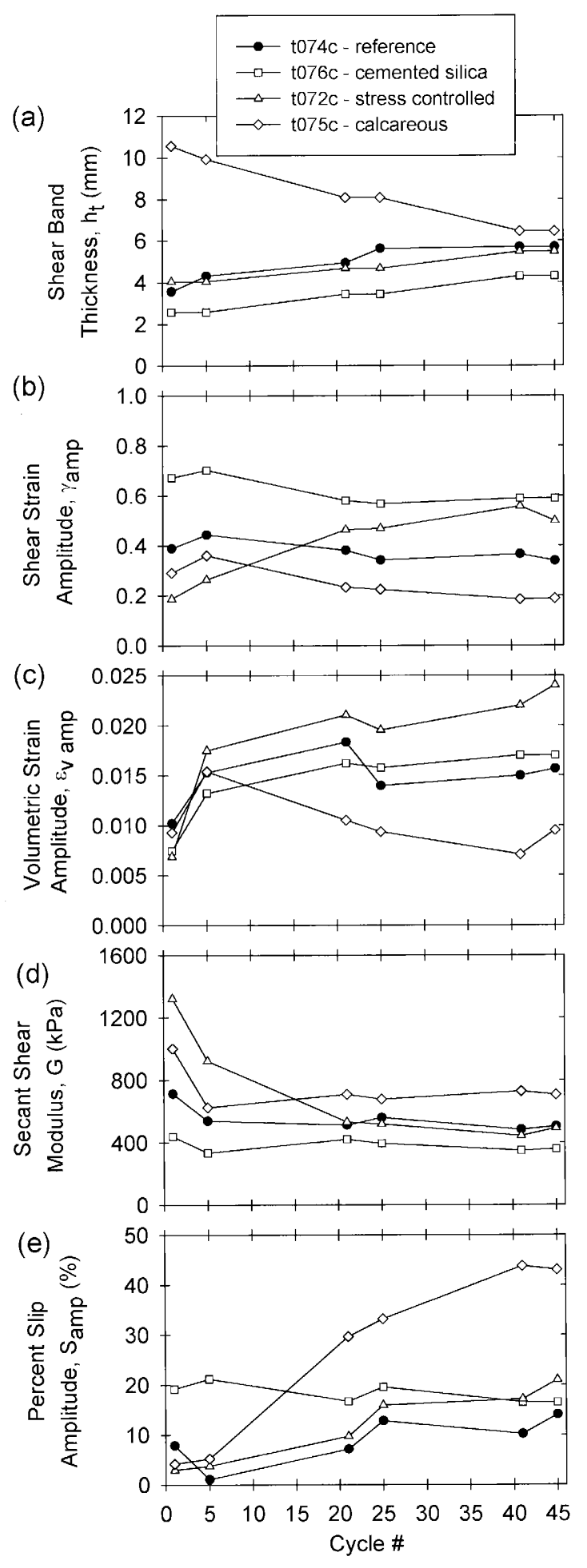

Fig. 6. Evolution of net local behavior versus cycle number

stress in later cycles that is less than $50 \%$ of the initial shear stress in cycle 1. Local measurements show that the calcareous soil (t075c) forms a thicker shear band, initially with a thickness of $10 \mathrm{~mm}$. This reduces to $6 \mathrm{~mm}$ after 40 cycles, but remains larger than the tests with silica sand. Consequently, the shear strain is distributed over a wider shear band, resulting in lower values of $\varepsilon_{\mathrm{v} \text { amp }}$ and $\gamma_{\text {amp. }}$. The rapid decrease of shear stress range $(\Delta \tau)$ in early cycles (Fig. 6(a)) is overcompensated by the reduction in $\gamma_{\text {amp }}$ (due to a sharp increase in $S_{\text {amp }}$ ). This results in a higher $G$ in later cycles for the calcareous soil relative to the silica sand.

Evolution of Local Behavior within an Individual Cycle

The evolution of behavior within an individual cycle was quantified through detailed analysis of cycles 1, 21, and 41 . The results presented in Fig. 7 focus on cycle 21, where each column contains results from a different test. The top row of plots contains the total horizontal displacement between the cyclic limit of $+1.0 \mathrm{~mm}$ and current horizontal displacement at the interface (e.g. $\delta_{\mathrm{h}}=0.5 \mathrm{~mm}$ reflects interface shearing from $+1.0 \mathrm{~mm}$ to $+0.5 \mathrm{~mm}$ ). The second row contains incremental horizontal displacements during the previous $0.1 \mathrm{~mm}$ of interface displacement (e.g. $\delta_{\mathrm{h} \text { inc }}=0.5 \mathrm{~mm}$ reflects shearing increment between $+0.6 \mathrm{~mm}$ and $+0.5 \mathrm{~mm}$ of horizontal interface displacement). Plots in rows three and four contain the companion set of plots for total and incremental vertical displacement, respectively. A selected set of $\delta_{\mathrm{h} \text { inc }}$ increments are plotted in order to provide clarity of trends while maintaining the ability to compare behavior between tests. For shearing in the opposite direction the trends are identical, but reversed.

\section{Horizontal Displacement and Shear Strain Evolution}

In all tests the horizontal displacement within the shear band per unit interface movement is constant through each cycle while the incremental horizontal displacement is almost independent of the position within the cycle (Fig. 7, second plot for all tests). This is shown by the uniform displacement gradient within the shear band for all displacement increments. There is no evidence of 'whipping', or delayed propagation of the interface shearing into the soil mass after shear reversal. Also, since the entire shear band continues to deform after $2 \mathrm{~mm}$ of interface movement; there is no evidence of a change in shearing mode to slip at the interface, with the shear band soil becoming decoupled. Instead, the similarity between incremental horizontal displacement contours indicates that the shear band thickness and percent slip is approximately constant for all increments. Lateral compression in the upper region continues throughout shearing as evidenced by small horizontal displacements in the upper portion of the specimen (Fig. 7, second plot for all tests). The greatest compression occurs within the first $0.2 \mathrm{~mm}$ after displacement reversal as the upper zone transfers some of the horizontal load to the opposite end wall of the shear box.

For the uncemented silica sand under displacement controlled shearing (t074c) (Fig. 7(a)), the compression in the upper region during the first two $0.1 \mathrm{~mm}$ increments is about $27 \%(0.027 \mathrm{~mm})$ of the displacement increment $(0.1 \mathrm{~mm})$ after which it decreases to around $10 \%(0.01$ $\mathrm{mm}$ ) of the displacement increment. In contrast, in the stiffer cemented specimen (t076c) (Fig. 7(b)), horizontal compression of the upper part of the specimen represents less than $10 \%$ of the interface movement during each 

(a)
Test t074c, Cycle 21 +/- $1 \mathrm{~mm}$, uncemented, silica

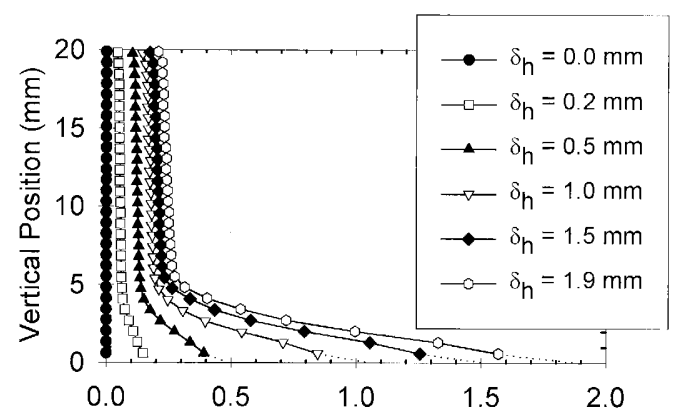

(b)

Test t076c, Cycle 21 +/-1 mm, cemented, silica
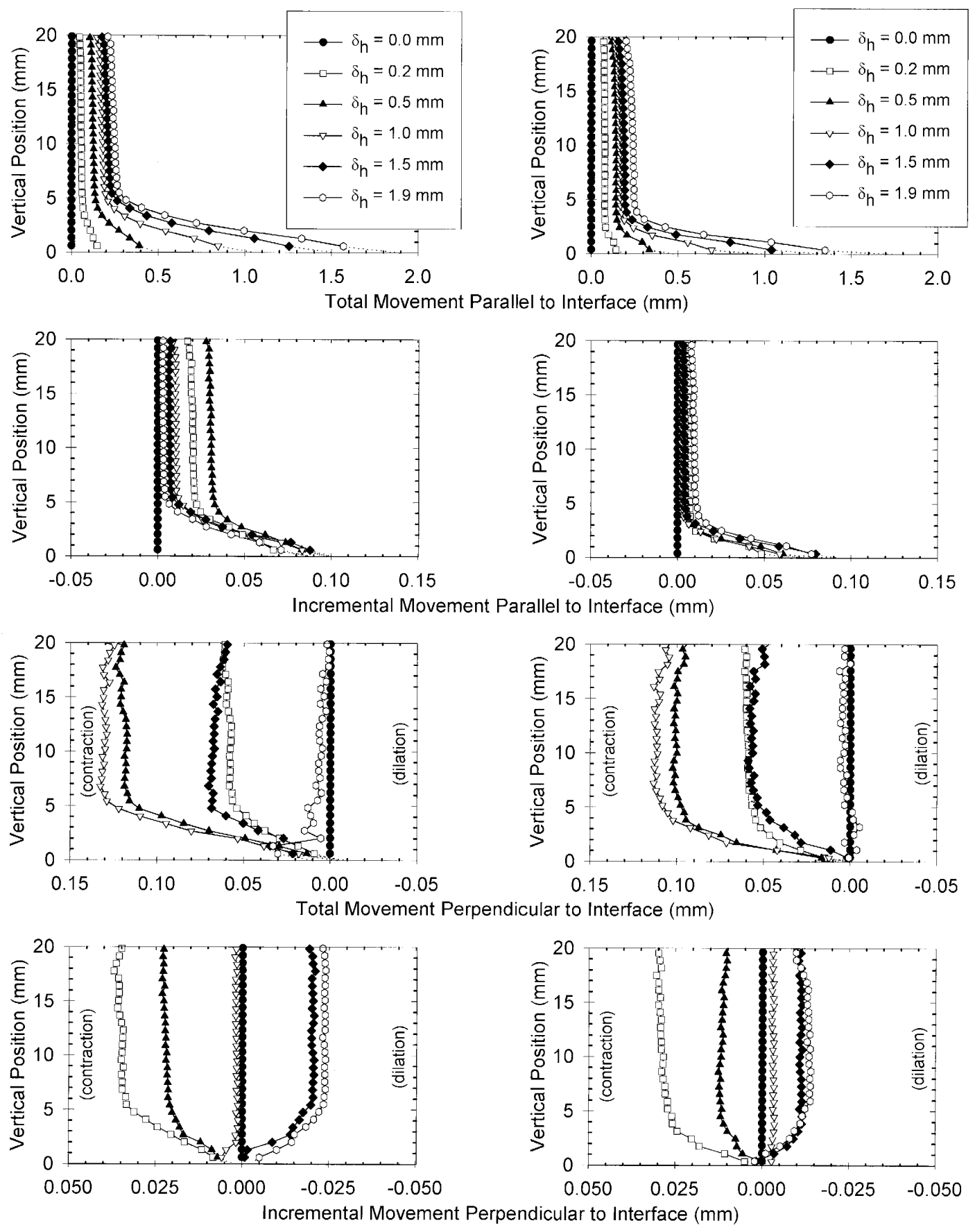

Fig. 7. Total and incremental horizontal and displacement contours for cycle 21 of all tests determined from PIV analysis (Continued)

increment. Comparing Figs. 7(a) and (b), the more localized deformation of the cemented specimen is evident. Compared to the uncemented case there is a sharper transition between the horizontal movement of the rigid (and presumably still cemented) upper part of the specimen and the shear band. In contrast, the shear band for the calcareous specimen is the least distinct and thicker, and does not show the distinct bi-linear displacement profile of the silica specimens. The higher initial thickness of the shear band for the calcareous specimen is attributed to greater interlocking due to the particle angularity, which causes transmission of displacements further from the interface surface. In the calcareous soil crushing occurs during cycling, which in turn gradually reduces interlocking and hence the shear band thickness.

\section{Vertical Displacement and Volumetric Strain Evolution}

The incremental specimen displacements perpendicular to the interface (Fig. 7(c) and (d)) are not constant through each cycle, unlike the horizontal movements. In 
(c) Test t072c, Cycle 21 +/- $125 \mathrm{kPa}$, uncemented, silica

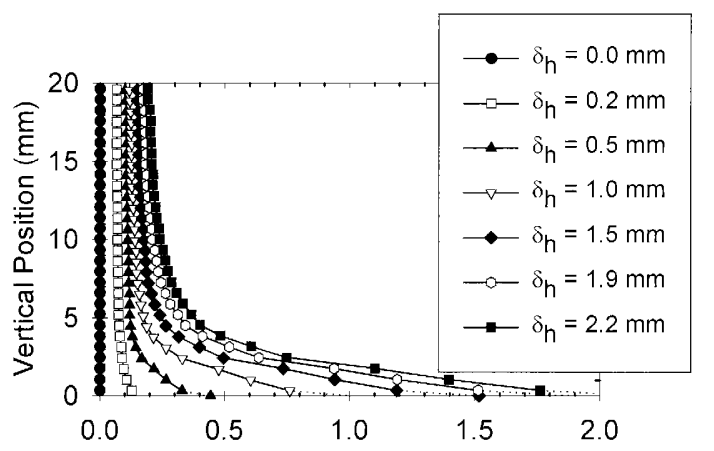

Total Movement Parallel to Interface $(\mathrm{mm})$

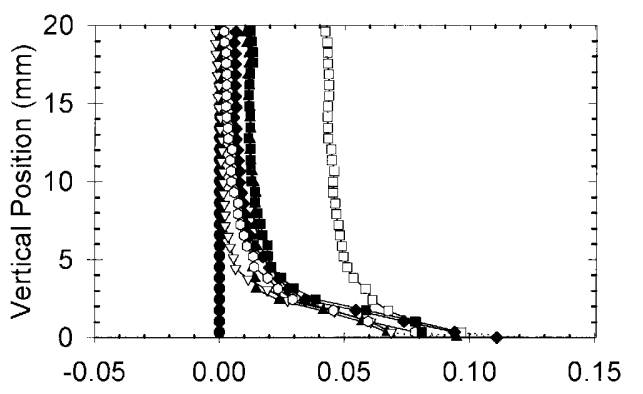

Incremental Movement Parallel to Interface (mm)

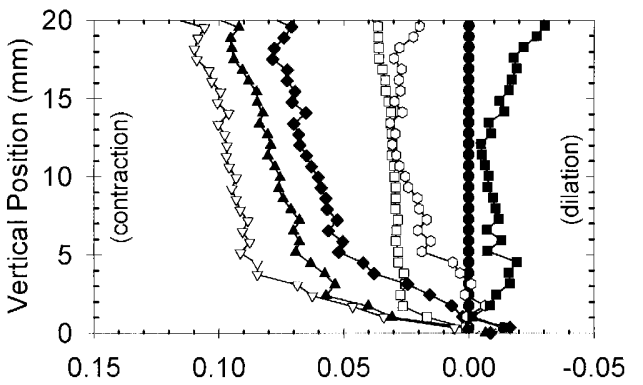

Total Movement Perpendicular to Interface $(\mathrm{mm})$
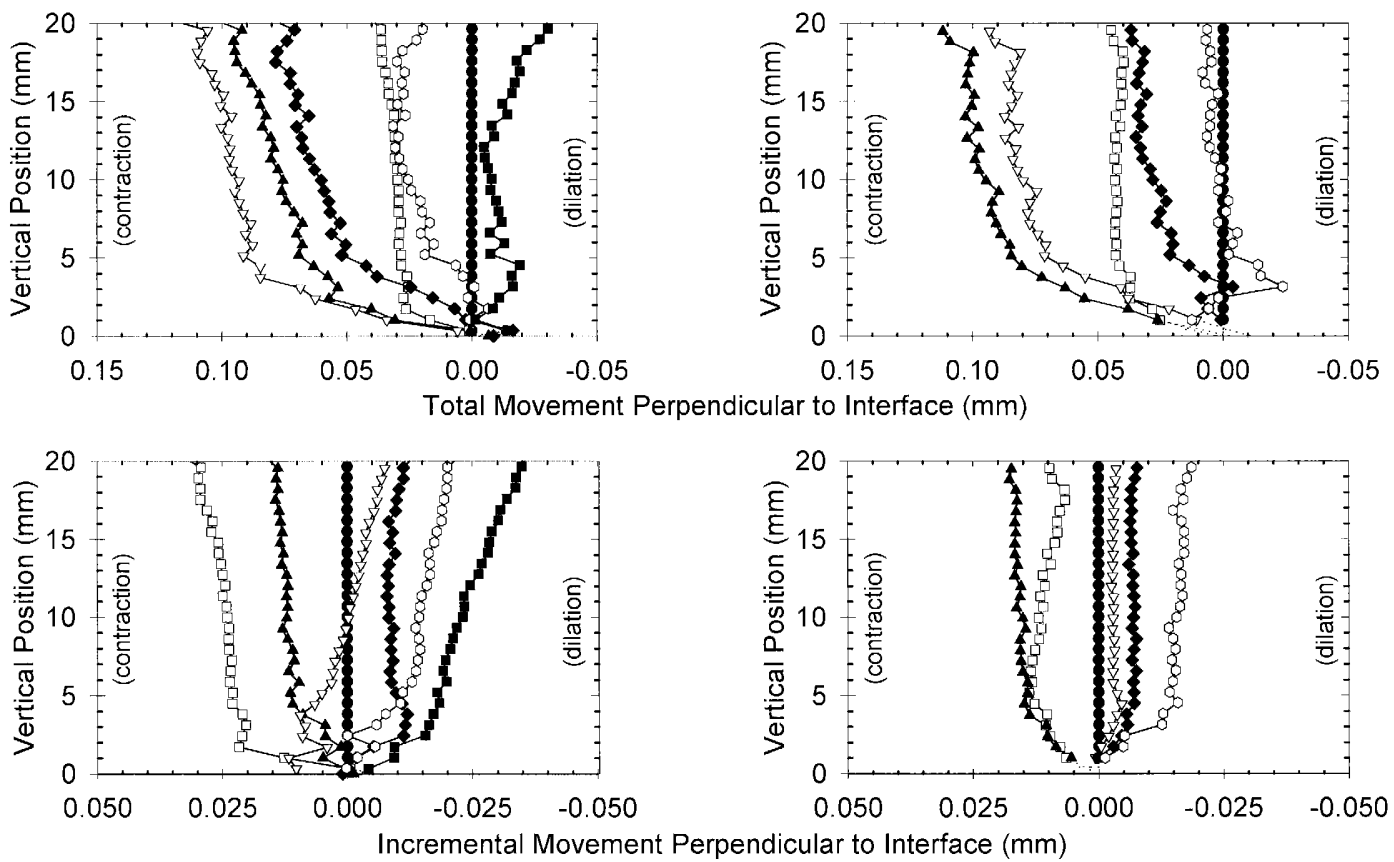

Fig. 7. (Continued)

all cases, the vertical displacement is constant throughout the upper part of the specimen, indicating that all volume change is concentrated within the shear band. Therefore, conventional external vertical displacement measurements (i.e. Fig. 3) are indicative of the vertical displacement at the top of the interface shear band.

A pattern of contraction followed by dilation is evident in all tests. The first two increments show contraction, the third increment shown $\left(\delta_{\mathrm{h}}=1.0 \mathrm{~mm}\right)$ corresponds to zero incremental volume change and the phase transformation point, and dilation occurs during the remainder of the cycle. Over the same period, the stress ratio decreases from failure in the previous direction $(\mu \approx-1.35$, Fig. 3$)$, through a phase transformation at a stress ratio of $\mu \approx+0.5$, to failure on the opposite side of the envelope $(\mu \approx+1.35)$. This stress-dilatancy response is typical for interfaces, and a flow rule of this general form has been proposed by Ghionna and Mortara (2002). Such flow rules are usually formulated or verified in terms of interface displacement rather than shear and volumetric 
strain within the soil. However, the local measurements presented in this paper allow the stress-dilatancy response to be quantified in terms of changes in volumetric strain and voids ratio, since the shear band thickness can be observed. As a result, the realism of such models can be improved since limits on the volumetric response can be drawn from maximum and minimum voids ratio tests.

\section{Relation between Behavior Evolution and Net Behavior per Cycle}

The specimen response during cyclic interface shearing has been identified through the sequential analysis of four tests with consideration of the global specimen behavior (Figs. 3 and 4), the net internal behavior per cycle (Fig. 6), and the evolution of behavior within an individual cycle (Fig. 7). The external response is related in a simple manner to the local evolution of behavior within the deforming shear band. Characterization of the local behavior using GeoPIV has shown that:

- Shear band thickness $\left(h_{\mathrm{t}}\right): h_{\mathrm{t}}$ is generally constant with cycle number. There is some evidence of increasing localization in calcareous sand, although this is clouded by the ill-defined extent of the shear band. A shear band thickness of 5 to $7 \times D_{50}$ has been determined from GeoPIV and is in good agreement with previous measurements (e.g. Frost et al., 2004).

- Incremental shear strain $\left(\gamma_{\text {inc }}\right): \gamma_{\text {inc }}$ is constant within a cycle is regardless of position between shearing limits, for cycles of amplitude $+/-1 \mathrm{~mm} \cdot \gamma_{\mathrm{amp}}$ can be estimated from $\gamma_{\text {inc }}$ and visa versa considering the number of increments within the displacement range of interest.

- Incremental percent slip ( $S_{\text {inc }}$ ): $S_{\text {inc }}$ within a cycle is constant regardless of position between shearing limits. $S_{\text {amp }}$ per cycle, determined using GeoPIV between the cycle limits, evolves with cycle number.

- Incremental volumetric strain $\left(\varepsilon_{\mathrm{v} \text { inc }}\right): \varepsilon_{\mathrm{v} \text { inc }}$ varies within an individual cycle, following a stress ratiodilatancy response of contraction followed by dilation after phase transformation at a stress ratio of about 0.5 . This response was determined based on local GeoPIV analysis and confirmed by global vertical displacement of the specimen. GeoPIV analysis allows the increase in density of the shear band to be quantified, as the band approaches the limiting maximum density with increased cycling. The incremental volumetric strain $\left(\varepsilon_{\mathrm{v} i n c}\right)$ and the maximum volumetric strain $\left(\varepsilon_{\mathrm{v} \text { amp }}\right)$ can be estimated from the interface shear band thickness and external measurements through $\varepsilon_{\mathrm{v} \text { inc }}=\varepsilon_{\mathrm{vinc}} / h_{\mathrm{t}}$ and $\varepsilon_{\mathrm{v} \text { amp }}=$ $\varepsilon_{\mathrm{v} \text { total }} / h_{\mathrm{t}}$, respectively.

\section{MODELING}

The progressive reduction in normal and shear stress during interface cycling under CNS conditions arises from the cumulative contraction of a well defined shear band adjacent to the interface. GeoPIV analysis quantitatively demonstrates that the specimen deformation is

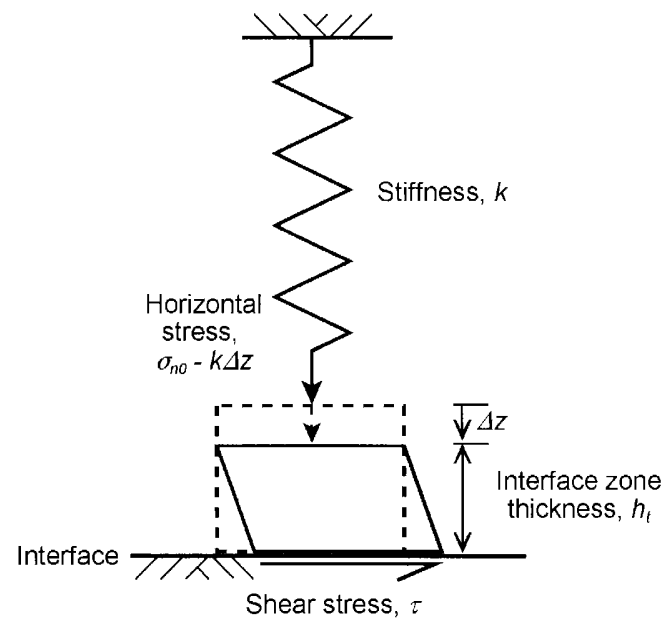

Fig. 8. Schematic of idealization of interface system

concentrated within a thin interface shear band, typically several mean particle diameters $\left(D_{50}\right)$ in thickness, and enables the interface shear band thickness to be monitored throughout cycling. Prior to these micro-scale observations, only mean changes in voids ratio of the entire specimen could be made, which would underestimate the contraction of the localized shear band. The progressive cycling of the interface leads to a net contraction of the interface shear band, and hence a reduction in interface normal stress. It is this reduction in normal stress that governs the loss of interface strength.

The system can therefore be modeled as an interface, of thickness $h_{\mathrm{t}}$, that is dilating and contracting within each cycle leading to a cumulative net contraction by distance $\Delta z$ (Fig. 8). After a specimen contraction of $\Delta z$ from an initial specimen void ratio of $e_{0}$, the void ratio of the interface shear band, $e_{\mathrm{sb}}$, is:

$$
e_{\mathrm{sb}}=\left(1-\frac{\Delta z}{h_{\mathrm{t}}}\right)\left(1+e_{0}\right)-1
$$

Permissible values of $e_{\mathrm{sb}}$ lie between the maximum and minimum void ratios of the specimen. An additional limit is the no-tension condition for drained (or dry) sand, so $\Delta z$ cannot take a value greater than $\sigma_{\mathrm{n} 0} / k$. Conventional practice is to define the $e_{\min }$ and $e_{\max }$ limits following the ASTM (2004) procedures. $e_{\min (A S T M}$ is obtained by vibrating a specimen under a known weight corresponding to a normal stress of $\sim 13.8 \mathrm{kPa} . e_{\max @ \text { ASTM }}$ is obtained by a sand deposition into a known volume using a funnel or an open cylinder about 0.6 times the diameter of the mold. Since the sand falls onto a slope at the angle of repose, the resulting state can be likened to a critical state at a very low stress (equal to about $1 \mathrm{kPa}$ at mid-depth of specimen). Correlations assembled by Cubrinowski and Ishihara (2000) suggest that the critical state voids ratio as effective stress tends to zero is slightly lower than $e_{\max }$ and corresponds to a relative density of about $10 \%$ in clean silica sands (e.g. Lee and Seed, 1967; Verdugo and Ishihara, 1996). Others have related the CSL to $e_{\max }$ at a nominal stress of typically $1 \mathrm{kPa}$ (e.g. 


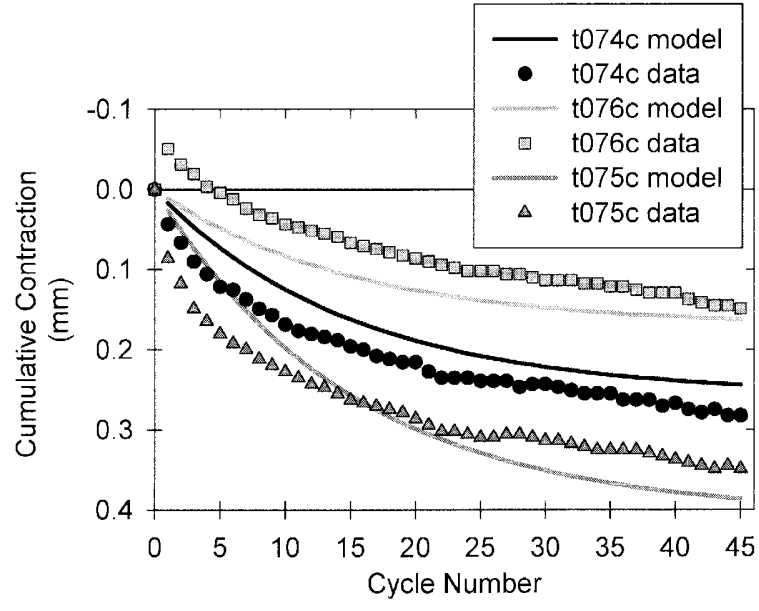

Fig. 9. Comparison of cyclic degradation model with experimental results

Klotz and Coop, 2002). Void ratios slightly higher than $e_{\max @ \text { ASTM }}$ can be achieved through other deposition conditions and can occur locally in laboratory specimens following shearing (e.g. Frost and Jang, 2000). Void ratios lower than $e_{\min (3) \mathrm{AST}}$ may be achieved at high stress levels and are associated with particle breakage. Breakage increases the coefficient of uniformity, which in turn reduces $e_{\min }$. For CNS interface testing, an appropriate $e_{\min }$ value may be defined as the void ratio at which further cyclic loading at a given stress level will induce no additional volume change. The ASTM $e_{\min }$ test provides a suitable value of $e_{\min }$ for the stress level of $\sim 13.8 \mathrm{kPa}$; the variation of $e_{\min }$ with stress level is discussed below. In CNS tests, during monotonic shearing to failure, the deforming soil close to the interface will shear towards a critical state.

A simple model is proposed whereby the specimen contraction over a single cycle is defined as a fixed fraction, $1 / N_{\text {char }}$, of the potential change in density during contraction to $e_{\min }$.

$$
\frac{\Delta e_{\mathrm{sb}}}{\Delta N}=e_{\mathrm{sb}(\mathrm{N}+1)}-e_{\mathrm{sb}(\mathrm{N})}=-\frac{1}{N_{\mathrm{char}}}\left(e_{\mathrm{sb}(\mathrm{N})}-e_{\min }\right)
$$

where $\Delta e_{\mathrm{sb}} / \Delta N$ is the change in shear band void ratio per cycle, $e_{\mathrm{sb}(\mathrm{N}+1)}$ is the shear band void ratio at cycle $N+1$, and $e_{\mathrm{sb}(\mathrm{N})}$ is the shear band void ratio at cycle $N$. Integrating over $N$ cycles yields:

$$
e_{\mathrm{sb}}=e_{\min }+\left(e_{0}-e_{\min }\right) e^{-\mathrm{N} / \mathrm{N}_{\mathrm{char}}}
$$

where $N_{\text {char }}$ is a characteristic number of cycles. Combining Eqs. (2) and (4) enables the evolution in $\Delta z$ with $N$ to be found. A reasonable fit to the specimen contraction data of the three displacement controlled CNS tests (Fig. 4(b)) is found by using the shear band thickness $\left(h_{\mathrm{t}}\right)$ reached at the end of each test (Fig. 6(a)) and a characteristic number of cycles $\left(N_{\text {char }}\right)$ equal to 15 as shown in Fig. 9 (input data in Table 2). The expression follows the degradation trend reasonably well aside from differences due to dilation in the first cycle which are not explicitly accounted for in this analysis. Only test t075c (carbonate
Table 2. Summary of input parameters for cyclic degradation model

\begin{tabular}{cccccc}
\hline Test \# & Sand type & $h_{\mathrm{t}}(\mathrm{mm})$ & $e_{\min }{ }^{1}$ & $e_{\max }{ }^{1}$ & $e_{0}$ \\
\hline t074c & IMDEX 16-30 & 6.0 & & & \\
t076c & IMDEX 16-30 & 4.0 & 0.500 & 0.679 & 0.567 \\
t075c & LeGendre 16-30 & 6.0 & 0.639 & 0.957 & 0.758 \\
\hline
\end{tabular}

${ }^{1} \operatorname{ASTM}(2004)$

sand) is divergent from the model in the later cycles. This divergence arises because the $e_{\min }$ value $(0.639)$ for calcareous sand compared to the initial state $\left(e_{0}=0.758\right)$ requires a specimen contraction of $0.41 \mathrm{~mm}$, which exceeds the no-tension limit of $\sigma_{\mathrm{n} 0} / k$ by $0.01 \mathrm{~mm}$. Therefore, Eq. (4) does not fully capture behavior in the later cycles of test t075c.

The above contraction model can be explored further to predict the lower limit of the interface normal stress at the end of a cyclic test. The CNS spring stiffness, $k$, links specimen contraction with loss of interface normal stress, $\sigma_{\mathrm{n}}$, defining the test path in specimen height $-\sigma_{\mathrm{n}}$ space. Noting that the specimen contraction is limited to the shear band, the test paths can be recast as straight lines in $e_{\mathrm{sb}}-\sigma_{\mathrm{n}}$ space with gradient $1 / h_{\mathrm{t}} k$ by combining the CNS condition (Eq. (1)) with the idealized interface system (Eq. (2)) (Fig. 10(a)):

$$
e_{\mathrm{sb}}=e_{0}-\left(\frac{\sigma_{\mathrm{n} 0}-\sigma_{\mathrm{n}}}{k \cdot h_{\mathrm{t}}}\right) \cdot\left(1+e_{0}\right)
$$

Equation (5) reveals the link between shear band thickness, confining stiffness and the degradation of interface normal stress with change in voids ratio. For a given change in $e$, any increase in shear band thickness $\left(h_{\mathrm{t}}\right)$ or CNS stiffness $(k)$ leads to a greater loss of interface normal stress, since the test path gradient, $1 / h_{\mathrm{t}} k$, is flatter in $e_{\mathrm{sb}}-\sigma_{\mathrm{n}}$ space. A corresponding upper bound value of $\sigma_{\mathrm{n}}$ can be defined on the test path at the intersection with the CSL, which represents a critical state condition that is achieved following sufficient monotonic shearing.

The degradation of $\sigma_{\mathrm{n}}$ with cycling can be predicted by combining Eqs. (4) and (5), leading to:

$$
\sigma_{\mathrm{n}}=\sigma_{\mathrm{n} 0}-k h_{\mathrm{t}} \frac{\left(e_{0}-e_{\min }\right) \cdot\left(1-e^{-\mathrm{N} / \mathrm{N}_{\text {char }}}\right)}{\left(1+e_{0}\right)}
$$

It should be noted that the void ratio $e_{\mathrm{sb}}$ referred to in Eq. (4) is the minimum value within a cycle, so Eq. (6) relates to the minimum normal stress within a cycle, not the value at failure.

The minimum value of $\sigma_{\mathrm{n}}$ that can be achieved by cycling is the intersection of the test path with the line $e_{\min }$. It is likely that the variation in $e_{\min }$ with normal stress $\sigma_{\mathrm{n}}$ will reflect the conventional (monotonic) critical state line (CSL). It is found that the CSL is straight in $e-\ln \sigma$ space at high stresses, and flattens at low stresses, tending to a value close to the $e_{\max (\text { ASTM }}$ value. For more breakable sands, the transition in the CSL occurs at lower stresses, reflecting the earlier onset of particle breakage.

Over the stress range of interest in this paper $(0-100$ $\mathrm{kPa}$ ), the gradient of the CSL for typical sands is $\sim 0.005$ 


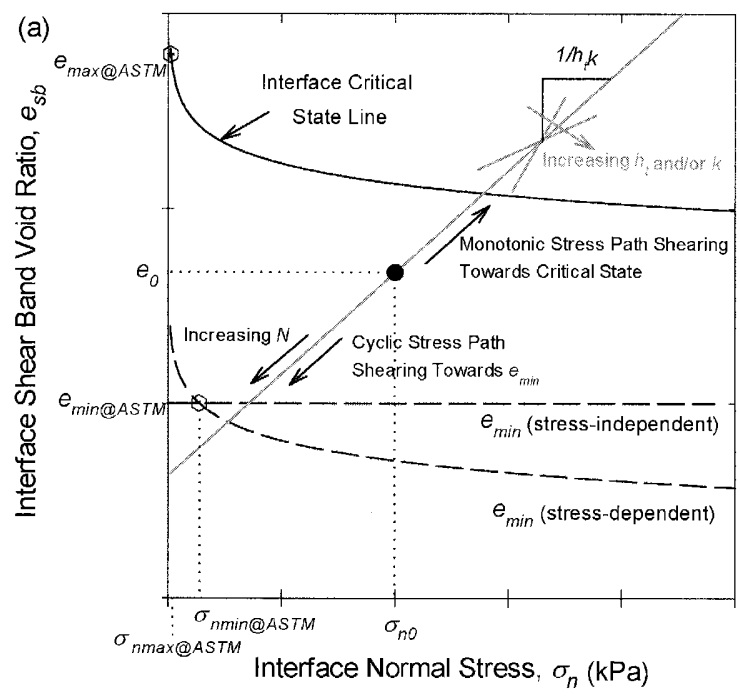

(b)

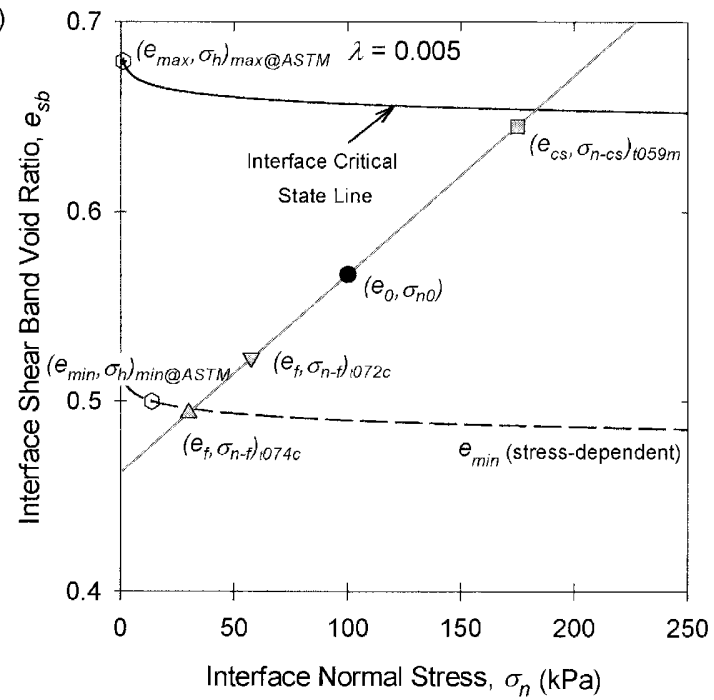

(c)

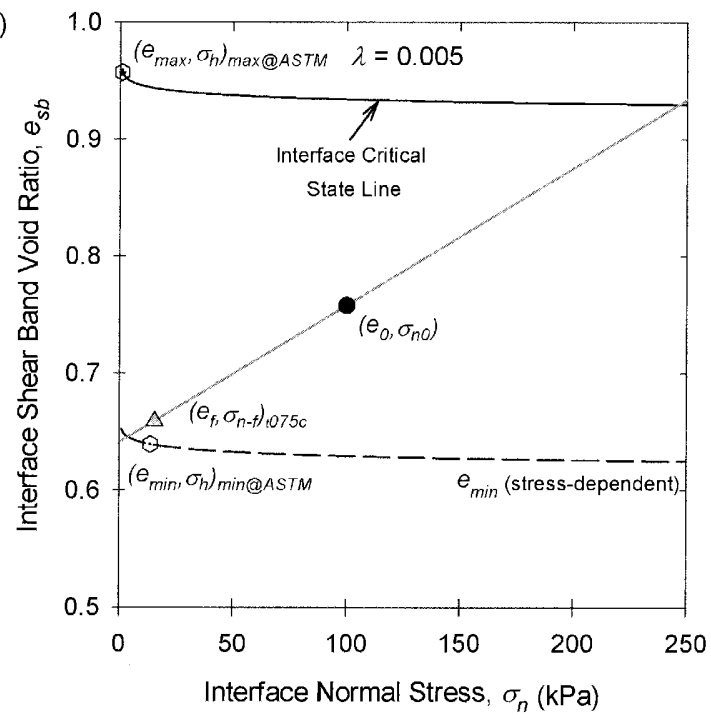

Fig. 10. (a) Schematic of interface critical state model, (b) Model with data from uncemented silica sand tests $t 074 \mathrm{c}$, t072c, and $t 059 \mathrm{~m}$, and (c) Model with data from calcareous sand test t076c in $e-\ln p^{\prime}$ space. At higher stresses this gradient typically increases to $\sim 0.05$. In this paper, as is conventional, the symbol $\lambda$ is used for the gradient of the critical state line. However, a value of $\lambda=0.005$ is used, representative of the low-stress region of the CSL under consideration, and not the more conventional value at high stresses.

Two forms of the $e_{\min }$ line in $e-\ln \sigma_{\mathrm{n}}$ space are considered herein. Firstly, a stress-independent value for which $e_{\min }=e_{\min @ \mathrm{ASTM}}$. An alternative $e_{\min }$ line is tentatively proposed to run parallel to the CSL passing through $e_{\min (3)}$ ASTM. It is recognized that the exact curvature of the alternative $e_{\min }$ line may differ from, and not be exactly parallel to, the CSL. However, without further data a stress dependent $e_{\min }$ line parallel to the CSL is assumed and is given by:

$$
e_{\min }=e_{\min (\mathrm{ASTM}}-\lambda \cdot \ln \left(\frac{\sigma_{\mathrm{h}}}{\sigma_{\mathrm{nmin}(@ \mathrm{ASTM}}}\right)
$$

A corresponding conventional critical state line can be defined using a slope $\lambda=0.005$ passing through the $e_{\text {max@ASTM }}$ value at a nominal stress of $1 \mathrm{kPa}$ (Eq. (8)):

$$
e_{\mathrm{cs}}=e_{\max @ \mathrm{ASTM}}-\lambda \cdot \ln \left(\frac{\sigma_{\mathrm{n}}}{1 \mathrm{kPa}}\right)
$$

The reasonableness of this framework is examined by comparing the initial and final states of the shear band in the tests reported in this paper with the $e_{\min }$ lines and CSL described above (Fig. 10(b)). In the monotonic test on silica sand, t059m, reported by DeJong et al. (2003), the final state of the shear band lies close to the CSL. In the cyclic tests on silica sands $(\mathrm{t} 072 \mathrm{c}$ and $\mathrm{t} 074 \mathrm{c})$, the final states lie most of the way from the initial condition to the $e_{\min }$ line given by Eq. (7). The final state in test t074c lies below the $e_{\min (x) \text { ASTM }}$ value suggesting a stress dependency of $e_{\min }$, as proposed by Eq. (7). With further contraction, as indicated by the trend in Fig. 9, it is likely that the state in these tests will reach the stress-dependent $e_{\min }$ line.

For the case of carbonate sand, the test path is slightly flatter in $e-\ln \sigma_{\mathrm{n}}$ space due to the thicker shear band, and the potential contraction is greater since $e_{0}-e_{\min }$ is higher than for the silica sand (Fig. 10(c)). As a result, the end conditions for the test are governed not by potential contraction but by the no-tension condition, since the test path intersects the void ratio axis prior to reaching the $e_{\min }$ line. In this case, and for other cases in which there is a high confining stiffness, a thick shear band, or high potential specimen contraction, Eq. (3) is not an appropriate model for the normal stress degradation. Instead, the shear band can contract sufficiently to relieve completely the normal stress on the interface.

\section{CONCLUSIONS}

Analysis of a series of CNS interface tests has highlighted the influence of cementation, shearing mode, and soil type on the cyclic response of dry sand. Conventional external measurements of specimen deformation have been augmented by GeoPIV measurements of internal specimen deformation, as viewed through a transpar- 
ent window. These observations link the cyclic degradation of normal stress (as seen in these tests and on piles in sand) to the contraction of a thin shear band adjacent to the interface.

The conventional global observations highlighted the loss of normal stress as the specimen contracted with continued cycling. The cemented silica specimen exhibited a strong but brittle initial response, returning to the gentle contraction of the uncemented specimen. The carbonate sand showed greater contraction, and hence a more significant loss of normal stress.

The GeoPIV measurements showed that the shear and volume change of the specimen was concentrated within an interface shear band with a thickness of 5-7 particle diameters adjacent the interface. The interface shear band was clearly defined in the silica sand tests, with the deformation of the cemented specimen localizing closer to the interface. The shear band was less well-defined in the carbonate sand. The remainder of the specimen underwent slight horizontal compression as the shear load on the interface was transferred partly to the upper platen and partly to the end walls of the box.

During a single cycle, the volume change of the shear band comprised an initial contraction, until the phase transformation point was reached at a stress ratio of about 0.5 . Thereafter, the specimen dilated to the failure line and increased in volume, generating additional normal stress, until the cycling limit was reached. This stress-dilatancy response is typical for sand. During displacement-controlled cycling of amplitude $+/-1$ $\mathrm{mm}$, a net contraction occurred over a single cycle, leading to a progressive contraction of the specimen.

Since the GeoPIV observations permitted the shear band thickness to be measured, the contraction of the shear band could be quantified as a decrease in voids ratio. The limiting potential shear band contraction and hence loss of normal stress was also able to be quantified since voids ratio limits exist. A simple model for the progressive contraction of the shear band is used to illustrate this behavior. Also, an exponential decrease in shear band void ratio with number of cycles is shown to model the observed response. Two limiting end conditions are evident when the test path is plotted in normal stress-void ratio space. Under stiff confinement with a thick interface shear band and a low minimum voids ratio, progressive contraction leads to almost total loss of normal stress. Under more compliant confinement with a thin shear band and limited potential contraction of the sand, the maximum loss of normal stress arises from the intersection of the minimum voids ratio line with the test path imposed by the CNS condition.

The observations in this paper and the emerging framework of an interface shear band contracting towards a minimum void ratio clarify the mechanism of friction fatigue during installation and loading of displacement piles in sand.

\section{ACKNOWLEDGEMENTS}

This work has been jointly supported through a United States National Science Foundation International Research Fellowship (\#INT-0107341) and the Australian Research Council Center for Offshore Foundations Systems at the University of Western Australia. The PIV analysis was performed in part through the support of Giken Seisakusho Ltd., which is gratefully acknowledged.

\section{NOTATION}

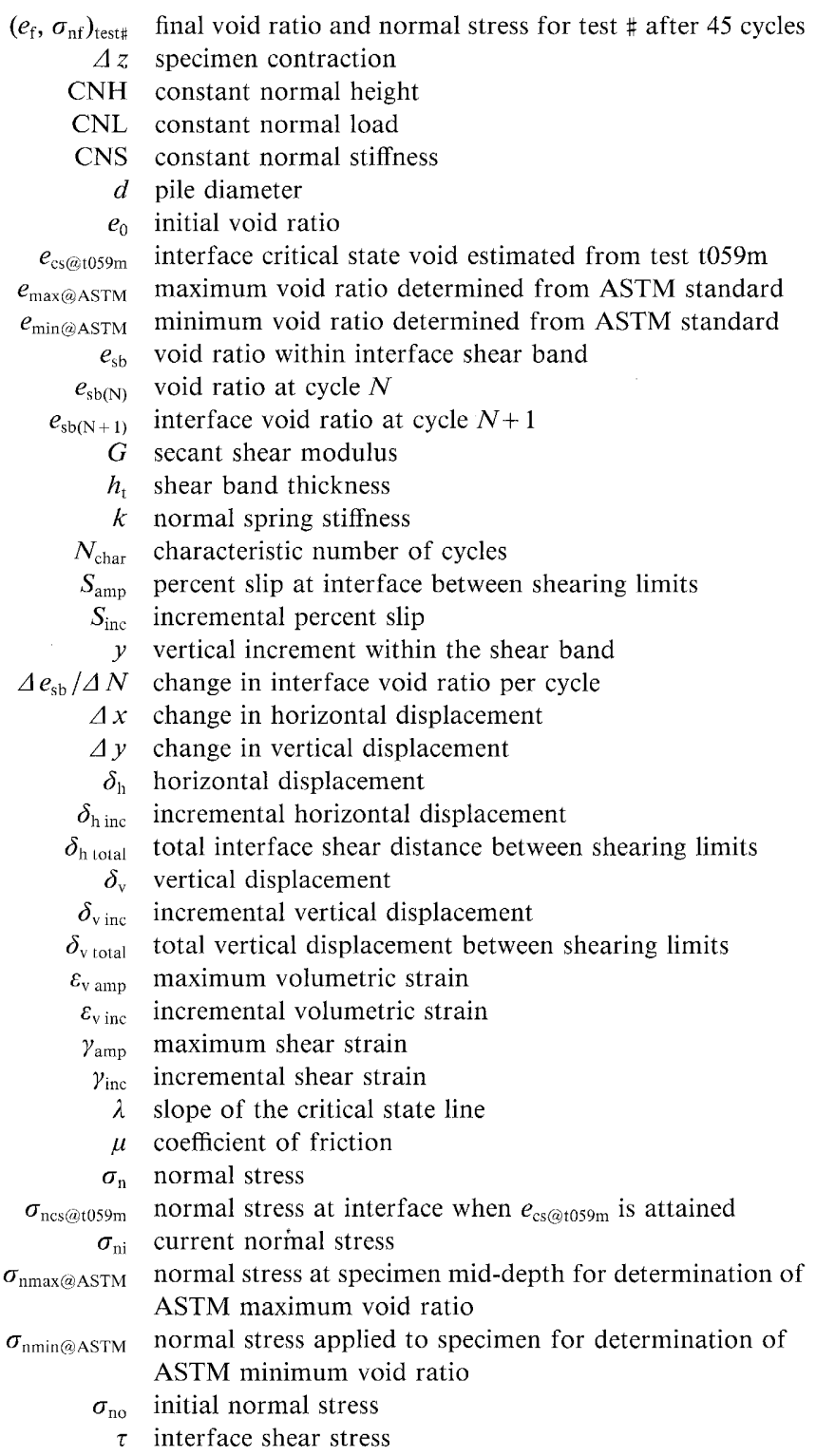

\section{REFERENCES}

1) Airey, D. W., Al-Douri, R. H. and Poulos, H. G. (1992): Estimation of pile friction degradation from shearbox tests, ASTM Geotech. Test. J., 15 (4), 388-392.

2) ASTM (2004): Annual Book of ASTM Standards, West Conshohocken, PA, 04.08.

3) Bolton, M. D. (1986): The strength and dilatancy of sands, Géotechnique, 36 (1), 65-78.

4) Boulon, M. and Foray, P. (1986): Physical and numerical simulation of lateral shaft friction along offshore piles in sand, Proc. $3 r d$ 
Int. Conf. Num. Meth. Offshore Piling, Nantes, France, 127-147.

5) Cubrinowski, M. and Ishihara, K. (2000): Flow potential of sandy soils with different grain compositions, Soils and Foundations, 40 (4), 103-119.

6) DeJong, J. T., Randolph, M. R. and White, D. J. (2003): Interface load transfer degradation during cyclic loading: a microscale investigation, Soils and Foundations, 43 (4), 81-94.

7) Frost, J. D. and Jang, D. J. (2000): Evolution of sand microstructure during shear, ASCE J. Geotech. Geoeviron. Engrg., 126 (2), 116-130.

8) Frost, J. D., Hebeler, G. L., Evans, T. M. and DeJong, J. T. (2004): Interface behavior of granular soils, 9th ASCE Aerospace Division International Conference on Engineering, Construction and Operations in Challenging Environments, Houston, TX, 8.

9) Ghionna, V. N. and Mortara, G. (2002): An elastoplastic model for sand-structure interface behaviour, Geotechnique, 52 (1), 41-50.

10) Jewell, R. J. and Randolph, M. F. (1989): Cyclic rod shear tests in calcareous sediments, Engineering for Calcareous Sediments, 2, 837-857.

11) Johnston, I. W., Lam, T. S. K. and Williams, A. F. (1987): Constant normal stiffness direct shear testing for socketed pile design in weak rock, Geotechnique, 37, 83-89.

12) Kelly, R. (2001): Development of a large diameter ring shear apparatus and its use for interface testing, PhD Dissertation, University of Sydney, Australia, 242.

13) Klotz, E. U. and Coop, M. R. (2002): On the identification of critical state lines for sands, ASTM Geotech. Test. J., 24 (3), 1-14.

14) Lee, S. W. (1998): Influence of surface topography on interface strength and counterface soil structure, Ph.D. Thesis, School of
Civil and Environmental Engineering, Georgia Institute of Technology, Atlanta, Georgia, USA, 336.

15) Lee, K. L. and Seed, H. B. (1967): Drained strength characteristics of sands, ASCE J. SMFE, 93 (SM6), 117-141.

16) Paikowsky, S. G., Player, C. M. and Connors, P. J. (1995): A dual interface apparatus for testing unrestricted friction of soil along solid surfaces, ASTM Geotech. Test. J., 18 (2), 168-193.

17) Potyondy, J. G. (1961): Skin friction between various soils and construction materials, Geotechnique, 11, 339-355.

18) Poulos, H. G. (1989): Cyclic axial loading analysis of piles in sand, ASCE Geotech. Engrg. J., 115 (6), 836-851.

19) Shahrour, I. and Rezaie, F. (1999): Experimental study of the behaviour of calcareous sand: structure interface, Proc. Engineering of Calcareous Sediments, 69-77.

20) Tabucannon, J. T. (1997): Shaft resistance of piles in sand, $P h D$ Dissertation, University of Sydney, Australia, 368.

21) Verdugo, R. and Ishihara, K. (1996): Steady state of sandy soils, Soils and Foundations, 36 (2), 81-91.

22) Vesic, A. S. (1972): Expansion of cavities in infinite soil mass, ASCE J. SMFE, 98 (SM3), 265-290.

23) White, D. J. (2002): An investigation into the behaviour of pressedin piles, $P h D$ Dissertation, Cambridge University, 384.

24) White, D. J., Take, W. A. and Bolton, M. D. (2001): Measuring soil deformation in geotechnical models using digital images and PIV analysis, Proc. 10th Int. Conf. Comp. Meth. Adv. Geomech., 997-1002.

25) White, D. J., Take, W. A. and Bolton, M. D. (2003): Soil deformation measurement using Particle Image Velocimetry (PIV) and photogrammetry, Geotechnique, 53 (7), 619-631. 